\title{
Sentinel Lymph Node Biopsy for Melanoma: Buggy Whip or Roller Bearing?
}

\author{
Giorgos C. Karakousis, $\mathrm{MD}^{1}$, and Mark B. Faries, $\mathrm{MD}^{2}$ \\ ${ }^{1}$ Perelman School of Medicine, University of Pennsylvania, Philadelphia, PA; ${ }^{2}$ The Angeles Clinic and Research Institute, \\ Cedars-Sinai Medical Center, Los Angeles, CA
}

In July 1903, at the Mack Avenue assembly plant in Detroit, the first automobile produced by the Ford Motor Company rolled off the line. Across the country, suppliers to the horse and buggy industry, then a dominant form of personal transportation, were generally unaware of this significant event. In Westfield, Connecticut, for example, over 40 buggy whip manufacturers were hard at work, while in Ohio, the Timken Company was producing roller bearings for carriage wheels. ${ }^{1}$ Just over a century later, Timken remains an industrial giant, relevant in numerous industries, with products in everything from surgical robots to rovers cruising the surface of Mars. Buggy whips? Not so much. In melanoma oncology, the genomic revolution and advent of effective systemic therapies are our Model Ts. It seems reasonable to ponder where sentinel lymph node (SLN) biopsy will be as melanoma care evolves. Continued relevance of the technique will depend on two things: demonstration of ongoing value, and innovation.

SLN biopsy has had a dramatic impact on the accuracy of staging in melanoma, ${ }^{2}$ and the pathologic status of the SLN is one of the most powerful prognostic variables, independent of other known factors. Evidence supporting this statement is extensive and includes innumerable retrospective series, reviews of large prospectively maintained databases, meta-analyses, and multiple prospective clinical trials. ${ }^{3-8}$ The prognostic effect of SLN biopsy varies with other tumor characteristics, such as

(C) Society of Surgical Oncology 2020

First Received: 25 March 2020;

Published Online: 9 June 2020

M. B. Faries, MD

e-mail: mfaries@theangelesclinic.org
Breslow thickness, with the most dramatic effect being in the intermediate-thickness range, but it is also strongly supported for both thin ${ }^{9-11}$ and thick ${ }^{12-14}$ melanomas.

SLN biopsy also appears to perform well relative to other less invasive technologies for nodal or prognostic assessment. Ultrasound, for example, has been used to evaluate regional nodes prior to SLN biopsy. Although it appears to be among the most sensitive imaging modalities for nodal evaluation, performance of ultrasound in the context of the second Multicenter Selective Lymphadenectomy Trial (MSLT-II) showed a sensitivity of only $6.6 \%$, with modest improvements for patients with higher-risk primaries. ${ }^{15}$ Other diagnostic tools such as multispectral photoacoustic imaging have shown some promise in preclinical models but their sensitivity and specificity remain to be seen in large patient experiences. ${ }^{16,17}$ Gene expression profiling (GEP) is also being developed as a potential non-invasive staging tool in melanoma. It appears likely that these tests will be able to provide prognostic information independent of other current variables, but the data available for these tests at present lack sufficient granularity to know exactly what their role will be. ${ }^{18}$

Innovation and adaptation will be necessary for continued relevance of SLN biopsy, which will likely take place in several areas. In the current issue of Annals of Surgical Oncology, Carvalho and colleagues present an evaluation of fluorescence lymphatic mapping using indocyanine green (ICG). ${ }^{19}$ It was hoped that use of ICG might facilitate SLN biopsy without the need for radioactive tracers. Although there is little radiation exposure with the standard procedure, elimination of radiotracers could simplify several aspects of the process, including scheduling, specimen handling, and waste disposal. Unfortunately, the results of their prospective comparison of mapping agents 
suggests ICG will not be a sufficient replacement for standard lymphoscintigraphy. Specifically, its sensitivity for SLN identification when considering all anatomic sites did not surpass that of radiotracer colloid. It would be interesting to know whether the addition of ICG might have other benefits, such as improving the completeness of SLN removal when combined with standard dyes (this may prove particularly useful in an era of fewer completion lymphadenectomies) or decreasing the time or extent of dissection required for the procedure. Additional research in these areas seems reasonable.

These would be incremental advances helping to optimize an already good technique. Other avenues of research could advance SLN utility even further. These include creation of more refined criteria for selection of patients for SLN biopsy, refining the prognostic implications of a positive or negative SLN using factors such as SLN tumor characteristics, and development of SLN markers that are predictive of response (or resistance) to adjuvant systemic therapies. Some of this work can probably be done with existing data sets; others will require additional translational and clinical research.

Patient selection for SLN biopsy has been largely determined by tumor thickness. While this is the most significant factor, other variables, including patient age, presence of lymphovascular invasion, ulceration status, mitotic rate, and perhaps GEP, may provide additional data to help refine selection parameters. Similarly, our understanding of the prognostic implications of a positive or negative SLN have improved and will likely continue to do so. For example, the current American Joint Committee on Cancer (AJCC) staging system incorporates not only the SLN status but also primary tumor characteristics in determining the appropriate substage of stage III for SLNpositive patients. ${ }^{4}$ SLN tumor burden also helps to risk stratify patients, with a $1 \mathrm{~mm}$ cut-off for the longest diameter of the largest focus being the most common measure (used in some adjuvant trials) for identifying higher-risk patients. ${ }^{20}$ Additional information about the area, focality, and location of nodal metastases has also been found to be prognostic. ${ }^{21}$

Another value of SLN biopsy is as a therapeutic intervention. The survival impact of early nodal treatment remains controversial. The absence of statistically significant survival benefit in prospective studies suggests any benefit would likely be small, although some subgroup analyses and meta-analyses leave open the possibility of a more significant impact in certain situations. ${ }^{5,22-24}$ However, the 'therapeutic' effect on regional disease control appears fairly clear. For example, in MSLT-II among nodepositive patients treated only with SLN biopsy and not complete lymph node dissection, the vast majority never recurred in their nodal basin, demonstrating that the SLN procedure alone had cleared their regional disease. ${ }^{25}$ No nomogram or biomarker will be able to accomplish that tangible and important goal for patients.

Finally, the SLN is the first site of interaction of a melanoma with the immune system. The nature of this interaction may provide insights about the nature of antitumor response and tumor-induced immunosuppression. Such features may not only reveal mechanisms of tumor progression, but they may also identify markers associated with benefit from current adjuvant therapies, allowing a more rational and cost-effective approach to selection of patients for adjuvant checkpoint blockade, targeted therapy, or observation. Ultimately, GEP of primary tumors combined with some assessment of the host's immune response (e.g. from germline DNA or peritumoral lymphocytes) may provide reasonably accurate assessments of an individual patient's risk for metastasis and likelihood of response to systemic therapies. Until such technologies materialize and mature though, identification of early metastasis in patients with clinically localized melanoma is one of the best biomarkers available to inform prognosis and guide treatment, and the SLN technique will likely remain a central part of patient care for the foreseeable future.

FUNDING Funding was provided by National Institutes of Health (Grant No. R01CA189163).

DISCLOSURE Mark Faries has been a member of advisory boards for Nektar Therapeutics, Sanofi, Bristol Myers Squibb, Array Bioscience, and Pulse Bioscience.

\section{REFERENCES}

1. Stross R. Failing like a buggy whip maker? Better check your simile. NY Times, New York, 2010.

2. Dessureault S, Soong SJ, Ross MI, et al. Improved staging of node-negative patients with intermediate to thick melanomas $(>1 \mathrm{~mm})$ with the use of lymphatic mapping and sentinel lymph node biopsy. Ann Surg Oncol. 2001;8:766-70.

3. Gershenwald JE, Scolyer RA, Hess KR, et al. Melanoma staging: evidence-based changes in the American Joint Committee on Cancer eighth edition cancer staging manual. CA Cancer J Clin. 2017;67:472-92.

4. Morton DL, Thompson JF, Cochran AJ, et al. Final trial report of sentinel-node biopsy versus nodal observation in melanoma. $N$ Engl J Med. 2014;370:599-609.

5. Gershenwald JE, Thompson W, Mansfield PF, et al. Multi-institutional melanoma lymphatic mapping experience: the prognostic value of sentinel lymph node status in 612 stage I or II melanoma patients. J Clin Oncol. 1999;17:976-83.

6. Balch CM, Gershenwald JE, Soong SJ, et al. Final version of 2009 AJCC melanoma staging and classification. J Clin Oncol. 2009;27:6199-206.

7. McMasters KM, Noyes RD, Reintgen DS, et al. Lessons learned from the Sunbelt Melanoma Trial. $J$ Surg Oncol. 2004;86:212-23. 
8. Doubrovsky A, De Wilt JH, Scolyer RA, et al. Sentinel node biopsy provides more accurate staging than elective lymph node dissection in patients with cutaneous melanoma. Ann Surg Oncol. 2004;11:829-36.

9. Wright BE, Scheri RP, Ye X, et al. Importance of sentinel lymph node biopsy in patients with thin melanoma. Arch Surg. 2008;143:892-9. discussion 899-900.

10. Mozzillo N, Pennacchioli E, Gandini S, et al. Sentinel node biopsy in thin and thick melanoma. Ann Surg Oncol. 2013;20:2780-6.

11. Han D, Zager JS, Shyr Y, et al. Clinicopathologic predictors of sentinel lymph node metastasis in thin melanoma. J Clin Oncol. 2013;31:4387-93.

12. Bello DM, Han G, Jackson L, et al. The Prognostic Significance of Sentinel Lymph Node Status for Patients with Thick Melanoma. Ann Surg Oncol. 2016;23:938-45.

13. Gyorki DE, Sanelli A, Herschtal A, et al. Sentinel lymph node biopsy in T4 melanoma: an important risk-stratification tool. Ann Surg Oncol. 2016;23:579-84.

14. Rondelli F, Vedovati MC, Becattini C, et al. Prognostic role of sentinel node biopsy in patients with thick melanoma: a metaanalysis. J Eur Acad Dermatol Venereol. 2012;26:560-5.

15. Thompson JF, Haydu LE, Uren RF, et al. Preoperative ultrasound assessment of regional lymph nodes in melanoma patients does not provide reliable nodal staging: results from a large multicenter trial. Ann Surg. Epub 7 Jun 2019. http://doi.org/10.1097/ SLA.0000000000003405.

16. Sinnamon AJ, Neuwirth MG, Song Y, Schultz SM, Liu S, Xu X, et al. Multispectral photoacoustic imaging for the detection of subclinical melanoma. J Surg Oncol. 2019;119(8):1070-76.

17. Stoffels I, Morscher S, Helfrich I, et al. Metastatic status of sentinel lymph nodes in melanoma determined noninvasively with multispectral optoacoustic imaging. Sci Transl Med. 2015;7(317):317.

18. Vetto JT, Hsueh EC, Gastman BR, et al. Guidance of sentinel lymph node biopsy decisions in patients with T1-T2 melanoma using gene expression profiling. Future Oncol. 2019;15:1207-17.
19. Carvalho CEB, Capuzzo R, Crovador C, et al. Near infrared (NIR) fluorescence is not a substitute for lymphoscintigraphy and gamma probe for melanoma sentinel node detection: results from a prospective trial. Ann Surg Oncol. Epub 7 Apr 2020. http://doi. org/10.1245/s10434-020-08409-6.

20. Voit CA, van Akkooi AC, Schafer-Hesterberg G, et al. Rotterdam Criteria for sentinel node (SN) tumor burden and the accuracy of ultrasound (US)-guided fine-needle aspiration cytology (FNAC): can US-guided FNAC replace SN staging in patients with melanoma? J Clin Oncol. 2009;27:4994-5000.

21. Cochran AJ, Wen DR, Huang RR, et al. Prediction of metastatic melanoma in nonsentinel nodes and clinical outcome based on the primary melanoma and the sentinel node. Mod Pathol. 2004; 17:747-55.

22. Santos-Juanes J, Fernandez-Vega I, Galache Osuna C, et al. Sentinel lymph node biopsy plus wide local excision vs. wide location excision alone for primary cutaneous melanoma: a systematic review and meta-analysis. $J$ Eur Acad Dermatol Venereol. 2017;31:241-6.

23. Hein DW, Moy RL. Elective lymph node dissection in stage I malignant melanoma: a meta-analysis. Melanoma Res. 1992;2:273-7.

24. Lens MB, Dawes M, Goodacre T, et al. Elective lymph node dissection in patients with melanoma: systematic review and meta-analysis of randomized controlled trials. Arch Surg. 2002;137:458-61.

25. Faries MB, Thompson JF, Cochran AJ, et al. Completion dissection or observation for sentinel-node metastasis in melanoma. N Engl J Med. 2017;376:2211-22.

Publisher's Note Springer Nature remains neutral with regard to jurisdictional claims in published maps and institutional affiliations. 